Pivoting the player: a framework for player character research in offline computer role-playing games

Sonia Fizek

Fizek, S., 2014. Pivoting the player: A framework for player character research in offline computer role-playing games. Journal of Gaming and Virtual Worlds. 6 (3): pp.215-234.

This is the author accepted version of the manuscript, (c) 2014 Intellect, the full version is available from:

doi:https://dx.doi.org/10.1386/igvw.6.3.215 1

Or: http://www.intellectbooks.co.uk/ 


\title{
Pivoting the player: A framework for player character research in offline computer role-playing games
}

This article has been published in the Journal of Gaming and Virtual Worlds (6.3)

\author{
Dr. Sonia Fizek \\ Leuphana University Lüneburg
}

\begin{abstract}
This article introduces a theoretical framework for the analysis of the player character (PC) in offline computer role-playing games (cRPGs). It derives from the assumption that the character constitutes the focal point of the game, around which all the other elements revolve. This underlying observation became the foundation of the Player Character Grid and its constituent Pivot Player Character Model, a conceptual framework illustrating the experience of gameplay as perceived through the PC's eyes. Although video game characters have been scrutinised from many different perspectives, a systematic framework has not been introduced yet. This study aims to fill that void by proposing a model replicable across the cRPG genre. It has been largely inspired by Anne Ubersfeld's semiological dramatic character research implemented in Reading Theatre I (1999) and is demonstrated with reference to The Witcher (CD Projekt RED 2007).
\end{abstract}

\section{Keywords}

player character, dramatic character, offline cRPGs, structural methodology, actant, actor

\section{Introduction}


Characters are the core elements in many video game genres, particularly the ones emphasising the importance of the storyline, the protagonist's development, or the art of simulation (e.g., computer role-playing games, massively online RPGs, action-adventures, first-person shooters, life-simulations, and multi-genre god games). From the player's perspective, the player character forms a crucial part of gameplay as they see the gameworld and act within it through the PC's eyes. Whether it is Commander Shepard (Mass Effect, BioWare 2007), a World of Warcraft (Blizzard Entertainment 2004) elfish protagonist, Niko Bellic (Grand Theft Auto IV, Rockstar North 2008), or a peculiar Spore (Maxis 2008) creature, their experiences constitute the focal point of the game.

Although player characters occur in all the above game types, no other genre features such a complex character development system as a computer role-playing game. Therefore, it constitutes an accurate research sample. The creation of the player character in cRPGs relies upon a levelling system based on experience points, and a rich customization process including the allocation of numerous attributes, and very often the adjustment of the PC's appearance, class, race, and name. Because the player is given a lot of freedom in the process of character creation, the PCs in cRPGs have the chance to become complex constructs rather than metres of a skilful hand-eye coordination of the player.

The diverse body of literature on video game characters accumulated in the past two decades seems to be unveiling an emerging pattern, according to which researchers scrutinise them. Some studies display a strictly mechanical approach to characters, and analyse them from the point of view of functions they perform within the gameworld, disregarding their representational traits (Aarseth 2004; Adams \& Rollings 2007; Frasca 2001; Howard 2008; Newman 2002; Novak \& Krawczyk 2005; Pisarski \& Sikora 2008).

Others focus on the characters as the drivers of agency, and emphasise the active role of the gamers who embody the PCs and make crucial decisions during the gameplay (Carr 2002; Lankoski 2003; Perlin 2004). Some researchers attribute agency to non-player characters, which, unlike player characters, are not controlled by the player, but by the game's AI (Parsler 2010). As far as agency and meaningful interaction are concerned, there have also been studies into video game character typology, based on the extent to which the players can interact with them (Egenfeldt-Nielsen et al. 2008; Wolf 2002).

In accordance with yet another perspective characters are viewed as representational gendered icons. A lot of studies have focused on the hyper-sexualised appearance of game characters (Rubenstein 2007; Schmieder 2009; Graner Ray 2004; Turkle 1984, 1995), or on the 
representation of female PCs (Cassell \& Jenkins 1999; Bryce \& Rutter 2005; Kennedy 2002; Richard \& Zaremba 2005; Schleiner 2000). Finally, characters have been viewed as the player's embodiment, in which case the double-situatedness of the body and the cybernetic feedback loop come into question (Boellstorff 2008; Dovey \& Kennedy 2006; Doyle 2009; Ensslin 2009; Morie 2007; Taylor 2002, 2004; Turkle 1999).

\section{Contribution to the field}

Although video game characters have been studied from so many different perspectives, so far an attempt to develop a replicable genre-focused model has not been made. This study aims to fill that void by proposing a toolkit for player character research in offline role-playing games. The overall structure of the Player Character Grid introduced in this article, combines two different analytical approaches that seem to prevail in VG studies - the structuralist (focused on rule mechanisms) and the cultural approach (related to socio-cultural meaning) (Bogost 2006; Dovey \& Kennedy 2006). Joining both perspectives allows encompassing the complexity of the player character and the medium it is expressed in.

The direct influence for my structural analysis comes from theatre theory. Anne Ubersfeld's semiological dramatic character research performed in Reading Theatre I (1999) constitutes the main driving force behind the structural part of the model of the PC in cRPGs.

\section{Theatrical Character Grid}

Ubersfeld's criticism of the concept of the dramatic character is comparable to the VG player character's experience on many levels, and may be used to support the structural part of the PC's analysis in video games. It should also be mentioned that the original research conducted in French in late 1970s, and translated into English in 1999, is not necessarily the most recent and certainly not the only theatrical study of structural nature. However, its core assumptions make it highly relevant and applicable to video games. Unlike in literary studies, the structuralist perspectives have prevailed and keep playing an important role in game studies, alongside cultural approaches. Ubersfeld's work should not be regarded as an outdated 1970's research perspective transplanted into video games, but rather as a conceptual framework and a trigger for the formal analysis of character creation in cRPGs. 
As Ubersfeld observes, 'contemporary semiology sees character as the locus of functions, and no longer as a substance-copy of a human being' (1999: 72). In other words, character analysis is not a discovery of pre-determined meaning, but rather a continuous construction of how character functions in individual scenarios and situations. This distinction seems to be accurate with reference to video games, where the actual character becomes three-dimensional only once it has been embodied by the player.

In order to explicate and establish the legitimacy of the terminology used in her detailed semiological methodology of the character, Ubersfeld drafted it visually on the Character Grid (Ubersfeld 1999: 79). Due to the spatial constraints of this article I will confine myself to the main driving principle of the model - the dynamic shift from the text towards the stage, and from the actant towards the actor.

Ubersfeld introduces two analytical orders to the methodology of the theatrical character 'textual' and 'staged'. The former scrutinises the character as an element within a literary text, while the latter focuses on the analysis of the persona exposed to the public gaze on stage. The live actor is placed in the centre of the Staged Semiotic Set, including all the listed aspects belonging to the two main dimensions. As Ubersfeld notices, " $[t]$ he character can thus be seen as the intersection (in the mathematical sense) of two semiotic sets (text and stage)' (1999: 80). To understand the significance of those two sets, it should also be emphasised that in the case of the former, the character operates in the actantial system (deep structure), while the latter implies the presence of the actorial system (surface structure) (1999: 77). The character's concrete existence is only possible in the stage set, and that is achieved by a concrete performance of an actor. The textual character constitutes merely a virtual entity (1999: 92).

In accordance with the terminology introduced by Algidras J. Greimas, an actant denotes the character's role associated with a certain function performed within the text. An actant should be differentiated from an actor, who is a concrete character placed in a concrete story. Transferring this juxtaposition to the video games realm, we may define an actantial figure in Grand Theft Auto IV as a lawbreaker and a war veteran, whereas his actorial realization would equate to Niko Bellic impersonated by the player, who shapes the player character through the choices made. The actantial system thus denotes an abstract construct while its actorial counterpart depicts a concrete character realised within a given gameworld.

In drama, all individual variables from the textual and the staged sets are mapped onto a live actor, who functions within the staged semiotic set. It is only on stage that a concrete character is realised through the process of theatricalization. As Ubersfeld concludes, '[w]e must return 
to the obvious fact that the character has a concrete existence through concrete performance alone; the textual character is only virtual' (1999: 92). This observation will take us to the world of cRPG games, in which the duality of the player character's persona - as it is in the case of a theatrical character - is a predominant feature.

\section{Player Character Grid}

A pre-designed player character (actant) is brought to life on the virtual stage by the player and as a result becomes an animated PC - a term I will use to refer to a video game equivalent of Ubersfeld's live actor. The process of PC animation or its in-game theatricalization is accompanied by the allocation of individual signs. Those visual and conceptual signifiers related to the PC's appearance customization and attribute modelling - change the in-game character from a pre-designed vessel; and a myriad of options to an actualised individual entity, controlled by a concrete player.

With reference to theatrical characters Ubersfeld discusses the importance of names and physical determinations, which are responsible for constructing an actor out of a character. Although name and appearance customizations are also crucial individuality indicators in many video games (Mass Effect, BioWare 2007; Neverwinter Nights, BioWare 2002; Fallout 3, Bethesda Game Studios 2008), the cRPG genre relies predominantly on extensive attribute allocation, and this feature makes cRPG characters so distinct, not only from their theatrical counterparts, but also from characters present in other video game genres, which do not require such a complex customization (e.g. action-adventure games, such as Prince of Persia, Ubisoft Montreal 2008; or Mirror's Edge, EA Digital Illustions CE 2008).

The first dimension of the player character analysis, related to Ubersfeld's semiological model, is demonstrated in the first part (PC - Structural Plane) of the Player Character Grid in figure 1. The methodological model consists of two planes, a structural and a referential one. The first one entails the Pivot Player Character Model, which perceives the character as

a functional element within the game system. The referential plane, on the other hand, places the character in a socio-cultural context, and allows for its wider interpretation surpassing the in-game system.

In accordance with the first level of the Grid, the player character is depicted as an integral element within the game as a system. Building upon Ubersfeld's theatrical character's 
methodology, the PC is analysed as an abstract actantial figure, and an actor/animated PC - its counterpart impersonated by a concrete player. Once the potential player character (actant) is embodied by the player, its structural analysis is conducted from a player-centric perspective.

Such a point of view requires the integration of other important in-game elements, which influence and co-create the player character's persona within the gameworld. The middle column refers to the framework needed to analyse the elements to the left and right.

\begin{tabular}{|c|c|c|}
\hline \multicolumn{2}{|c|}{ PC - STRUCTURAL PLANE } & \multirow{3}{*}{$\begin{array}{l}\text { PC as an element within } \\
\text { the game system }\end{array}$} \\
\hline $\begin{array}{l}\text { ACTANT } \\
\text { (abstract element } \\
\text { with a potential set } \\
\text { of attributes and } \\
\text { scenarios, placed } \\
\text { within a system) }\end{array}$ & \multirow{2}{*}{ 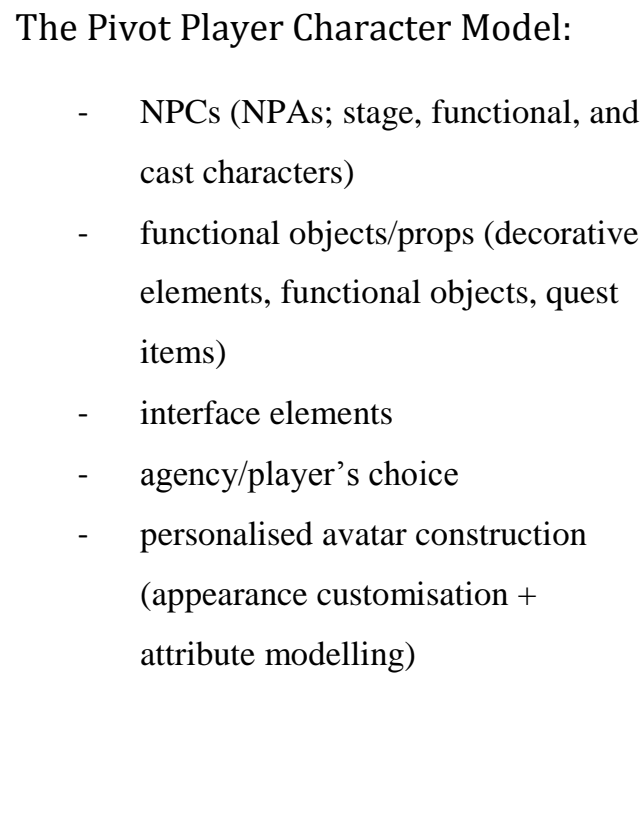 } & \\
\hline $\begin{array}{l}\text { ACTOR/ANIMATED } \\
\text { PC (an actant with } \\
\text { individual features } \\
\text { selected by the } \\
\text { player) }\end{array}$ & & \\
\hline \multicolumn{2}{|c|}{ PC - REFERENTIAL PLANE } & \multirow[b]{2}{*}{$\begin{array}{l}\text { PC as a concrete } \\
\text { realisation } \\
\text { of that element in the } \\
\text { socio- } \\
\text { cultural system }\end{array}$} \\
\hline $\begin{array}{l}\text { ANIMATED PC + } \\
\text { ACTOR + } \\
\text { CULTURAL } \\
\text { CONDITIONINGS }\end{array}$ & Selected Aspects of Cultural Theory & \\
\hline
\end{tabular}

Figure 1: The Player Character Grid in Video Games. 
The Referential Plane of the Player Character Grid portrays the PC, not as a mechanical element within the system, but as a concrete realization of that element in the socio-cultural context. Video games do not exist in a technological vacuum, and are in fact the products of culture, which influences the way characters are represented and interpreted (Newman 2004: 127-129). The Referential Plane thus may incorporate a wide spectrum of aspects of Cultural Theory into the analysis of the player character in a given video game. ${ }^{1}$ In this article I will not conduct an analysis based on the referential plane. Instead, I will eliminate the psychologising or psychoanalysing discourse constructed around the character (Ubersfeld 1999: 75) in order to demonstrate how the player character functions in the gameworld and what in-game components influence that functioning. The Structural Plane and its Pivot Model may contribute to further research and act as a peripheral frame for the interpretation practice that to borrow from literary theory - ' $\ldots$ organises perception without designating meaning' (Ramage 1986: 105).

It is also worth noticing how the PC's development progresses in accordance with the presented continuum between an actant and an actor/animated PC (structural plane), and an animated PC perceived through the cultural prism (referential plane). Those three different perspectives depict the player character first as a structural element with a predefined set of capabilities, then as a realised set of capabilities selected by a concrete player (the choices are narrowed down and an actant PC becomes an animated PC), and finally the PC reaches yet another level of individualization, by which a layer of culturally significant conditionings is added to the animated PC.

Using the example of Fallout 3 (Bethesda Game Studios 2008), we may identify a PC as an empty nameless vessel with a set of available attributes, perks and decisions, which later in the game will form it into a concrete character. Once the player impersonates the vessel, it becomes a Jenny (a possible name for our female avatar) with neutral Karma, a certain number of points allocated to: strength, perception, endurance, charisma, intelligence, agility, and luck (S.P.E.C.I.A.L), and a few items in the Pip-Boy's 3000 inventory. Once Jenny proceeds through the game, develops her skills, levels of morality (between -1.000 and +1.000 ) and makes choices that influence her relation to other in-game elements (NPCs), she and her decisions, as well as the reactions of NPCs, may be then interpreted according to a certain cultural scenario.

\section{Pivot Player Character Model}


The Pivot Player Character Model (the main toolkit in the structural plane of the Player Character Grid) encompasses five major building blocks: the player character itself, nonplayable characters, props and inventory, interface, and agency. The diagram in figure 2 illustrates the correlations between the individual elements of the model.

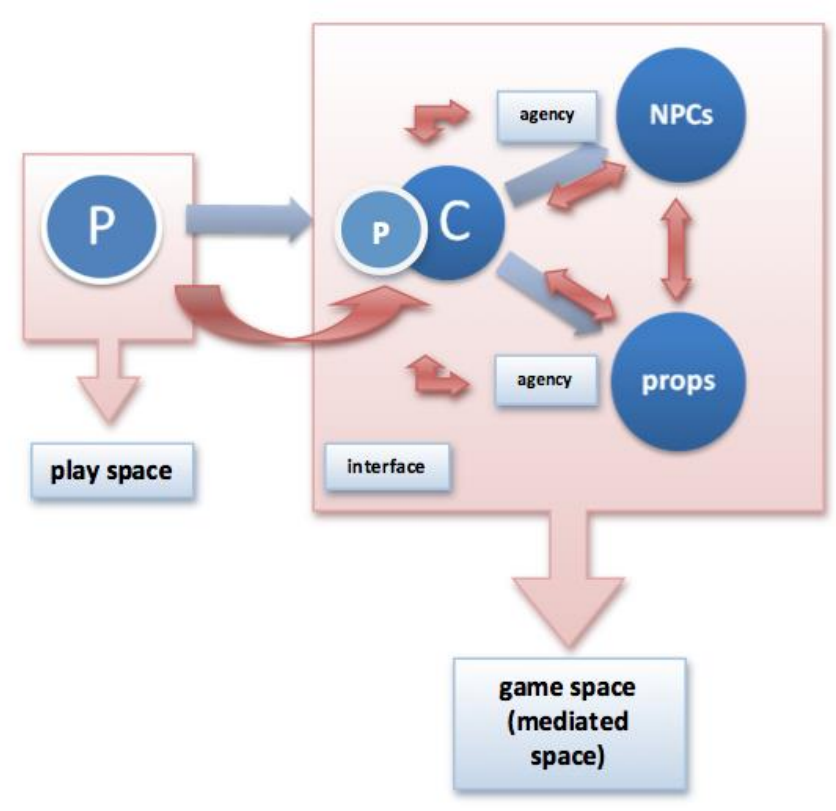

Figure 2: The Pivot Player Character Model.

The player character (PC) is the central point of the PPC Model. The other components, such as non-playable characters (NPCs) and objects or props revolve around it, and are analysed from the PC's perspective. ${ }^{2}$ The PC consists of two layers: a player (P) and a character, or avatar (C). Following Nitsche's representation of space in video games (2008:17), P belongs to the play space, which is external to the game space and includes the player and the video game hardware' (2008: 18).

C occupies the game space, or to be more precise the mediated space - 'the space of the image plane, $[\ldots]$ which consists of all the output the system can provide in order to present the rulebased game universe to the player' (2008: 18). Once the player adopts the identity of the character within a game, they (players) become its integral part and see the gameworld through the avatar's eyes.

Another dividing layer (or a joining one, depending on the theoretical perspective) between the player and the character persona relates to the interface, which enables the PC to experience the 
game space. ${ }^{3}$ The player exerts their control over the game's elements by means of agency, which is conveyed via the interface. Furthermore, in many games there is a constant interplay between NPCs (Artificial Intelligence) and props. NPCs have the ability to pick up certain objects and make use of them just in the same way a PC does. Manipulating the NPCs and props makes them responsive to the PC's actions, which is indicated by the red double pointed arrows in the diagram (PC $\leftrightarrow$ NPCs $\leftrightarrow$ props $\leftrightarrow$ PC). The interplay between the above elements (PC, NPCs, props) may be referred to as entity manipulation, which 'encompasses the alteration of the game made either by the player or by in-game entities' (Zagal et al. 2005: 5).

\section{Case study and terminology}

In case of role-playing video games, such as The Witcher, the designed character is an empty semiotic vessel (Rehak 2003: 173) unless embodied by the player. Since this moment of thrusting a virtual life into the character is a crucial turning point in the process of PC animation, this section will focus on selected aspects of an actualised PC and the experience of levelling up, assigning traits, and interacting with NPCs and props.

The table in figure 3 summarises the structural characterization of the PC on the basis of a few game specific elements extracted from the PPC Model and applied to selected scenes from the game's Chapter I: Outskirts of Vizima. Outlining the integral elements that shape the PC in the form of a table illustrates more clearly the complexity of the relations between the PC, in-game objects, and other non-player characters. Before discussing the construction of the PC, I shall explicate the meaning of the table's components.

Entities refer to all the in-game objects that may be modified and/or interacted with by the player, and they include NPCs, and various objects found in the gameworld (Zagal 2005: 5). It should be emphasised here that in-game objects gain ludic meaning and shape the PC predominantly when they are interacted with. This interaction may be referred to as entity manipulation. It consists of altering the attributes (e.g., owner, velocity etc.) or abilities (e.g., fight, drink, wear etc.) of the entities (Zagal 2005: 8). Entity manipulation may be also referred to in terms of interaction options (Consalvo \& Dutton 2006).

Applying the terminology introduced by Egenfeldt-Nielsen et al. (2008: 178-179) and Parsler (2011: 136-137), NPCs may be divided into: 
1. NPAs (non-player agents)/functional characters - they perform general functions within the gameworld, such as trading with the PC, distributing quests and quest items, displaying dialogue options.

2. Cast - they are assigned specific functions closely related to the story, such as fighting with the PC who can loot their bodies after a won duel, fist-fighting, playing dicepoker, getting drunk.

3. Stage - they constitute a part of the scenery and cannot be interacted with, for instance chickens, random villagers.

Here I would like to emphasise that the difference between functional and cast characters does not seem to be entirely clear. Both categories entail the character's functionality and its degree depends on whether the performed functions are general or specific. Neither Egenfeldt-Nielsen et al. (2008) nor Parsler (2011) provide a sufficient explanation of the difference between the two types. For instance, it is not apparent why the dialogue options constitute a determining factor in differentiating between functional and cast characters. Therefore, I modified the two categories and decided to allocate the NPCs to two groups based on the complexity of the interaction model. In the first group (functional) I place non-player characters that contribute to the PC's experience by offering quests, dialogue options crucial for the advancement of the storyline, or by distributing various items, which contribute to the development of the PC. The second category (cast) includes all the other NPCs who populate the gameworld and react to simple actions activated by the PC. In The Witcher cast characters usually entail generic opponents (Salamandra bandits), ghouls, various beasts, and random drunkards at the Inn.

Similarly to NPCs, the in-game inanimate objects or props fall under the following classification (Howard 2008: 77):

1. Functional - they have a direct impact on the PC's performance within the game, such as books and scrolls, food items, weapons.

2. Quest/plot items - they play an essential role in the back-stories behind quests; without them the quests cannot be completed and the plot does not advance.

3. Decorative - they constitute a part of the scenery.

Although both functional and quest/plot items can be interacted with by the PC (unlike decorative ones), the difference between them is related to the significance from the perspective of the plot. The objects in the second category can only be acquired after activating a specific quest and lose their functionality after its completion. For instance, once Geralt (the player character of The Witcher) lights up all the candles in the chapels surrounding the village in the 
Outskirts, they cannot be used by the PC on any other occasion. Functional objects, on the other hand, may be used irrespective of the quest that is currently fulfilled by the PC.

It should also be noted that functional and quest items have the ability to influence the character's development throughout the game. Applying Zagal's terminology, we notice that the PC's attributes may be either altered permanently (changing the PC's statistics) or temporarily (changing the PC's attributes for a short period of time) (Zagal 2005: 8).

In her structural theory Ubersfeld observes that characters do not operate in a void, but in a theatrical space filled with actors, accessories and decorative elements (1999: 120). According to her the relations between the character and the world may be perceived from the point of view of the objects existing within that world. 'Theatre can use an object strictly as decoration, as an aesthetic object, or it can use an object for the most utilitarian purposes' (1999: 120). Interestingly, her typology of theatrical objects overlaps to a certain degree with the above classification proposed by Howard (2008).

The last main category present in the table is connected with what Consalvo \& Dutton call interaction mapping, which 'involves examining the choices that the player is offered with regards to interaction not with objects, but with other player characters, and/ or with Non-Player Characters (NPCs)' (Consalvo \& Dutton 2006). This may include significant choices made by the PC on the basis of dialogue options related to particular NPCs.

As far as agency is concerned, we should focus on the question of the extent to which a PC may be individualised and shaped according to the player's will. The more freedom the player is given in customising and constructing their character, the more intricate the characterization process becomes, and the more diverse the gameplay. We may come to the conclusion that the more individuality indicators are present within an RPG, the bigger its replayability value.

A few fields have been marked in grey in order to signify the lack of interaction mapping. In accordance with this category the character impersonated by the player can only interact with the game's AI represented by other characters (functional and cast NPCs). Therefore, the inanimate elements, such as Objects and Selected Location cannot be analysed with reference to this category. Since stage characters do not react to the PC's actions, similarly to decorative objects, they cannot be interacted with. 


\begin{tabular}{|c|c|c|c|c|c|}
\hline $\begin{array}{l}\text { ENTITY } \\
\text { TYPE }\end{array}$ & $\begin{array}{l}\text { ENTITY } \\
\text { SUBTYPE }\end{array}$ & ENTITY & $\begin{array}{l}\text { GENERAL } \\
\text { DESCRIPTION }\end{array}$ & $\begin{array}{l}\text { ENTITY MANIPULATION (interaction } \\
\text { options) }\end{array}$ & INTERACTION MAPPING \\
\hline \multirow[t]{3}{*}{ NPCs } & $\begin{array}{l}\text { NPAs/ } \\
\text { Functional }\end{array}$ & Alvin & $\begin{array}{l}\text { Witch } \\
\text { Source (with } \\
\text { innate magical } \\
\text { abilities) }\end{array}$ & $\begin{array}{l}\text { The PC talks to Abigail. The PC buys a } \\
\text { few books from Abigail and brings her } \\
5 \text { petals of White Myrtle. The PC can } \\
\text { also have sex with the witch in the } \\
\text { cave. } \\
\text { The PC talks to Alvin and finds out the } \\
\text { source of the Beast (phase: Alvin's } \\
\text { Prophecy). }\end{array}$ & $\begin{array}{l}\text { Abigail appears in the Of Monsters } \\
\text { and Men quest (phases: White } \\
\text { Myrtle Petals, The Witch's } \\
\text { Innocence, The Witch is Cornered). } \\
\text { The PC needs to interrogate Alvin } \\
\text { to find out where the Beast came } \\
\text { from. The boy has to drink a } \\
\text { potion, for which Abigail needs } 5 \\
\text { petals of White Myrtle. The PC has } \\
\text { to collect or buy the Myrtle and } \\
\text { bring it back to the witch. The PC } \\
\text { considers Abigail not guilty of } \\
\text { summoning the Beast and helps } \\
\text { her escape the village. He also has } \\
\text { sex with her in the cave. }\end{array}$ \\
\hline & Cast & $\begin{array}{l}\text { Barghests } \\
\text { Beast }\end{array}$ & $\begin{array}{l}\text { Haunted } \\
\text { creatures } \\
\text { summoned by } \\
\text { the Beast } \\
\text { Also known as } \\
\text { hellhound }\end{array}$ & $\begin{array}{l}\text { The PC fights with them, kills them and } \\
\text { then loots their dead bodies (Barghest } \\
\text { skulls, Beast fangs, ectoplasm, and } \\
\text { Death Dust) } \\
\text { The PC fights with the Beast and kills it, } \\
\text { completing Chapter I. }\end{array}$ & $\begin{array}{l}\text { The interaction with cast NPCs } \\
\text { does not lead to any significant } \\
\text { choices. The beasts and other } \\
\text { creatures can only be fought with, } \\
\text { while dialogue options with Olaf or } \\
\text { Salamandra bandits in Chapter I do } \\
\text { not have any implications on the } \\
\text { storyline. }\end{array}$ \\
\hline & Stage & Chickens & $\begin{array}{l}\text { Scattered } \\
\text { around the } \\
\text { village }\end{array}$ & $\begin{array}{l}\text { Stage NPCs cannot be interacted with } \\
\text { and serve a decorative purpose in the } \\
\text { gameworld. }\end{array}$ & \\
\hline
\end{tabular}




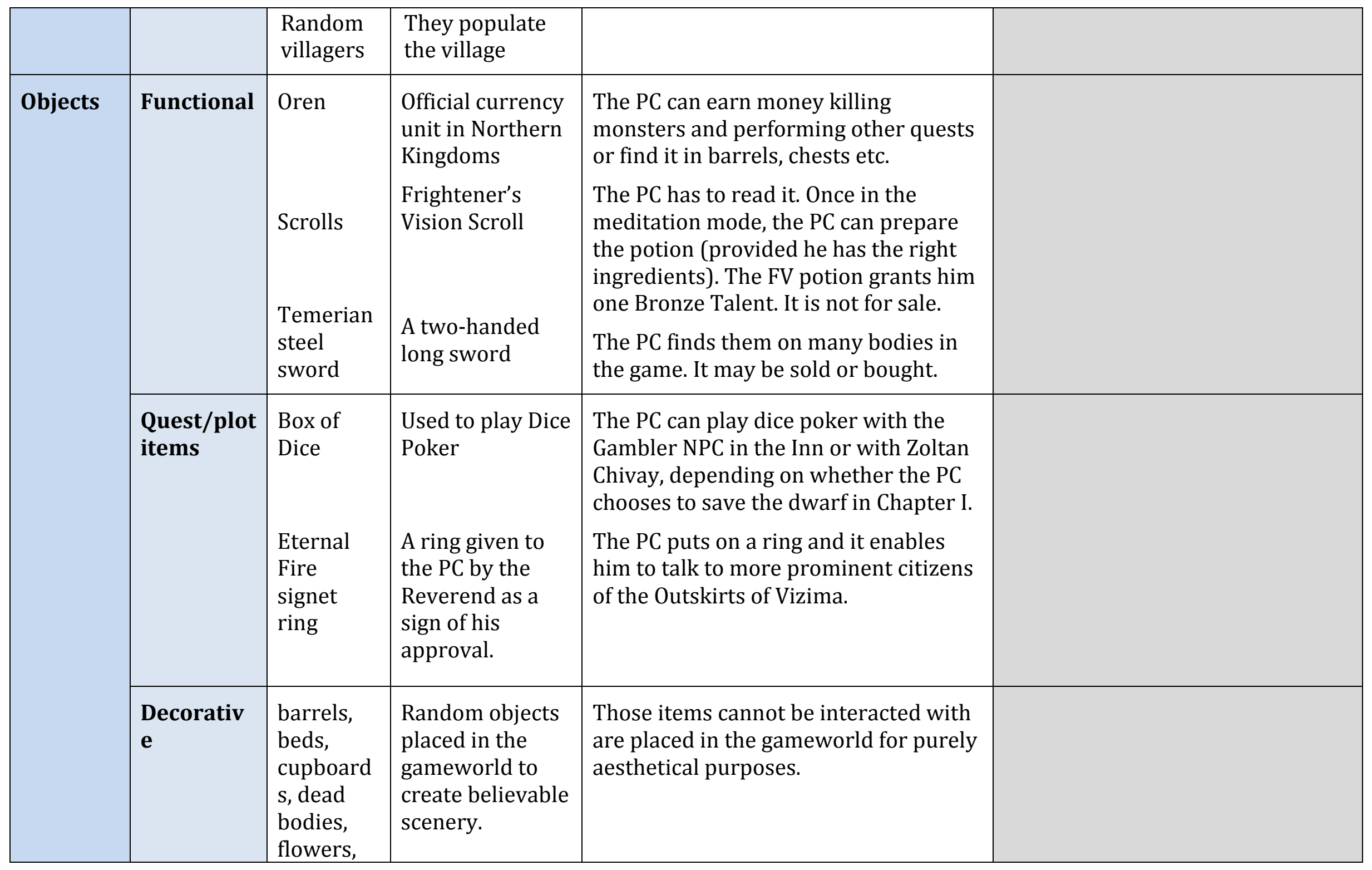




\begin{tabular}{|l|l|l|l|l|l|}
\hline & $\begin{array}{l}\text { househol } \\
\text { d items, } \\
\text { trees, and } \\
\text { others }\end{array}$ & $\begin{array}{l}\text { Selected } \\
\text { locations }\end{array}$ & $\begin{array}{l}\text { The } \\
\text { Outskirts } \\
\text { of Vizima } \\
\text { (there are } \\
\text { 58 active } \\
\text { locations } \\
\text { he PC can } \\
\text { interact } \\
\text { with) }\end{array}$ & $\begin{array}{l}\text { Odo's } \\
\text { house }\end{array}$ & $\begin{array}{l}\text { Geralt enters the house, talks to the } \\
\text { witch and buys an item from her } \\
\text { (Herbalism Book for 200 Orens). } \\
\text { Abigail need White Myrtle to make a } \\
\text { potion for Alvin (Quest: Of Monsters } \\
\text { and Men) }\end{array}$ \\
\hline
\end{tabular}

Figure 3: Selected NPCs, objects, locations and emerging scenarios from Chapter I of The Witcher (2007). 


\section{The Witcher}

The game's story and main characters have been inspired by "The Witcher" (1990), a collection of short stories by Andrzej Sapkowski, a Polish fantasy writer. The opening sequence of The Witcher adapts Sapkowski's first story of the same title, depicting the adventures of Geralt of Rivia, who is asked to cure King Foltest's daughter Adda of a fatal curse that turned her into a fierce monster referred to as Striga. The overall gameplay, although based on the above literary piece, diverges from it and directs the characters towards entirely new plot paths. The introductory cutscene pictures Geralt's successful battle with Striga. The protagonist does not kill the monster but instead cures her with the help of magical signs and turns her into a human being again. Several years pass after the encounter with Striga and one day Geralt is found unconscious on a field by his fellow witchers. He is transported to the witcher's fortress of Kaer Morhen.

The present case study does not include a preliminary character's appearance customization present in many other cRPG games, such as Fallout series, Dragon Age, and Mass Effect. Since Geralt performs a culturally and intertextually precoded role, a pre-designed conceptual and visual set of attributes belonging to the PC does not allow for full avatar customization. Due to a closed template of the storyline, which is based on a literary character, the process of individualization of the character by means of arbitrary names or physical determinations is not available. As Adams \& Rollings observe, using such predefined characters 'enables the designer to tell a story in which the avatar already has a past and relationships with other characters when the game begins' (2007: 527). In The Witcher an individualised animated PC is created by the player on the level of attribute modelling (which differs depending on the player's preferences), and choices influencing the storyline, made in the critical moments of the game (e.g., when Geralt has to abide by one of the fractions of the conflict - The Squirrels or the Order of the Flaming Rose).

The case of the PC development presented here focuses on selected scenarios from Chapter I taking place at the Outskirts of Vizima, the capital city of Temeria. ${ }^{4}$ The Prologue in Kaer Morhen (the witcher's fortress) consists of numerous introductory cut-scenes and tutorials, therefore it has not been selected for this analysis. Arriving at the Outskirts, the PC is still a relatively unformed character, with only a few talents assigned to the four basic skills (strength, dexterity, stamina, intelligence), and an elementary knowledge of the Aard magical sign (level 1 out of 5), which was unlocked by Leo (non-player agent) in the Prologue. Geralt is also acquainted with a few non-player characters (Vesemir, Lambert, Leo, Eskel, Triss 
Merigold, Azar Javed, Professor, Salamandra bandits, and Savolla mage). However, it is in Chapter I that the actual development of the player character begins.

As may be observed from the table in figure 3, the player character's formation is a complex process based on the PC's interaction with the gameworld and the player's choices made within it. This meaningful interaction with the functional in-game elements is what defines the PC's development, which is illustrated by means of various interface components. Figure 4 summarises Geralt's development path reached at the end of Chapter I of the game.

\begin{tabular}{|c|c|}
\hline Interface Category & Development Elements \\
\hline Character Development Tree & $\begin{array}{l}\text { Level: Novitiate Witcher level 7; } 28.000 \text { XP } \\
\text { Attributes: Strength level 2; Dexterity level 2; Stamina level } \\
\text { 2; Intelligence level } 2 \\
\text { Signs: Aard level 2; Igni level } 2 \\
\text { Steel Sword: Strong Steel level 2; Fast Steel level 2; Group } \\
\text { Steel level } 2 \\
\text { Silver Sword: Strong Silver level 1; Fast Silver level 1; } \\
\text { Group Silver level } 2\end{array}$ \\
\hline Inventory & $\begin{array}{l}1017 \text { Orens, Temerian steel sword, the witcher's steel } \\
\text { sword, leather jacket, torch }\end{array}$ \\
\hline Quest items & $\begin{array}{l}\text { Letter of Save Conduct, box of dice }(\mathrm{x} 4) \text {, key to the } \\
\text { Salamandra hideout, Eternal Fire signet ring, candles, white } \\
\text { myrtle }\end{array}$ \\
\hline Satchel & $\begin{array}{l}\text { Barghest skull (x10), Salamandra brooch (x6), scrolls } \\
\text { (Frightener's Vision Scroll, the Book of the Swallow, } \\
\text { Hellhound's Soul, the Book of the Tawny Owl), chicken, } \\
\text { grapes, water, book (Portrayal of Witchers), silver ruby } \\
\text { ring, sapphires, local pepper vodka, flint (x11), Kaedwen } \\
\text { stout, white vinegar (Vitriol), powder, phosphor } \\
\text { (Vermilion) }\end{array}$ \\
\hline Journal & $\begin{array}{l}\text { Characters: Abigail, Alvin, Azar Javed (Prologue), Berengar } \\
\text { (Prologue), Eskel (Prologue), Lambert (Prologue), Leo } \\
\text { (Prologue), Professor (Prologue), Triss Merigold (Prologue), } \\
\text { Vesemir (Prologue), Haren Brogg, Kalkstein, Mikul, Odo, } \\
\text { Shani, Reverend, Zoltan Chivay } \\
\text { Places: Kaer Mohren (Prologue), Lab (Prologue) Temeria, } \\
\text { Outskirts of Vizima, Inn, Crypt (only the major places are } \\
\text { listed in the Journal; minor locations may be viewed on the } \\
\text { maps) } \\
\text { Bestiary: Frightener (Prologue) } \\
\text { Recipes: Blizzard, Frightener's Vision, Hellhound's Soul, } \\
\text { Potion for Triss (Prologue; quest item), Swallow, Tawny } \\
\text { Owl, Thunderbolt, White Gull, White Honey }\end{array}$ \\
\hline
\end{tabular}


Figure 4: Player Character Development Path in Chapter I of The Witcher.

The above table presents the PC's development as it is visible within the game's interface. One has to realise, however, that the characterization process is far more complex and goes well beyond the elements listed in the interface. Geralt's overall development is shaped by:

1. Progression level (e.g. Novitiate Witcher level 7 at the end of Chapter I) and the accumulation of experience points (XP).

2. Talent distribution across four attributes, four signs, and fighting styles (see Character Development Tree).

3. NPCs met and locations visited during the gameplay (they form the character's knowledge of the world and may be accessed via the Journal: Characters, Places, Bestiary; the complex interrelations between those elements may be viewed in figure $3)$.

4. Significant functional objects accumulated in the inventory.

5. Significant choices triggered by the selected dialogue lines.

The first three points, addressed in figure 4, may be viewed directly from the level of in-game interface. Although the same may be said about point four, it differs from the previous ones in that the importance and meaning of the objects collected by the PC cannot be extrapolated directly from their graphical representation or description provided in the inventory. Their significance upon the characterization process of the PC may be detected only in the context of actions associated with them. As previously mentioned in the Terminology section, some entities, when manipulated, may alter the PC's attributes. The following list in figure 5 includes selected objects that cause temporary or permanent changes in Geralt in Chapter I of The Witcher:

\begin{tabular}{|l|l|l|}
\hline Object & Temporary change & Permanent change \\
\hline Alcohol (e.g., Temerian rye, & $\begin{array}{l}\text { Temporarily raises } \\
\text { Kaedwen stout) }\end{array}$ & \\
& $\begin{array}{l}\text { PC's vision and slows down } \\
\text { his reaction time, which may } \\
\text { affect the outcome of a fight, } \\
\end{array}$ & \\
& $\begin{array}{l}\text { e.g. killing Echinops after } \\
\text { drinking with Odo. }\end{array}$ & \\
\hline
\end{tabular}

\footnotetext{
${ }^{1}$ Kaedwen Stout (The Witcher) - an alcoholic beverage originating from the largest of the Northern Kingdoms.
} 


\begin{tabular}{|c|c|c|}
\hline Torch & $\begin{array}{l}\text { Temporarily changes the } \\
\text { surroundings by illuminating } \\
\text { them, and enhances Geralt's } \\
\text { vision during a fight. }\end{array}$ & \\
\hline $\begin{array}{l}\text { Alchemical substances (e.g., } \\
\text { aether, rebis, white vinegar, } \\
\text { vitriol) }\end{array}$ & $\begin{array}{l}\text { When combined with } \\
\text { alchemical knowledge and } \\
\text { necessary ingredients make } \\
\text { up various potions } \\
\text { temporarily enhancing } \\
\text { Geralt's combat skills. }\end{array}$ & \\
\hline $\begin{array}{l}\text { Potions (e.g., Swallow, } \\
\text { Tawny Owl, Thunderbolt, } \\
\text { White Gull) }\end{array}$ & $\begin{array}{l}\text { Cause temporal attribute } \\
\text { changes, for instance } \\
\text { Swallow enhances the } \\
\text { regeneration of Geralt's } \\
\text { Vitality (hit points) for the } \\
\text { duration of } 2 \text { hours within } \\
\text { the game. }\end{array}$ & \\
\hline $\begin{array}{l}\text { Food (e.g., watermelon, } \\
\text { chicken, grapes) }\end{array}$ & $\begin{array}{l}\text { Causes temporary } \\
\text { regeneration of Vitality. }\end{array}$ & \\
\hline Box of dice & $\begin{array}{l}\text { When used in a poker game } \\
\text { with other NPCs, may either } \\
\text { make the PC win or lose } \\
\text { money (temporary change). }\end{array}$ & $\begin{array}{l}\text { In the long run, the won } \\
\text { matches contribute to Geralt's } \\
\text { development as a dice poker } \\
\text { player (The Novice, The } \\
\text { Professional, The Sharper, } \\
\text { The Legend). }\end{array}$ \\
\hline $\begin{array}{l}\text { Books and scrolls (e.g., } \\
\text { Frightener's Vision Scroll, } \\
\text { The Book of the Swallow, } \\
\text { Hellhound's Soul, The Book } \\
\text { of the Tawny Owl) }\end{array}$ & & $\begin{array}{l}\text { Permanently change the state } \\
\text { of Geralt's knowledge about } \\
\text { the gameworld, and some of } \\
\text { them equip him with potion } \\
\text { recipes. }\end{array}$ \\
\hline $\begin{array}{l}\text { Quest items (e.g., Letter of } \\
\text { Save Conduct, key to the } \\
\text { Salamandra hideout, Eternal } \\
\text { Fire signet ring, candles) }\end{array}$ & & $\begin{array}{l}\text { Necessary to proceed in the } \\
\text { storyline and character } \\
\text { development. }\end{array}$ \\
\hline
\end{tabular}

Figure 5: Temporary and Permanent Changes.

The above examples demonstrate how the interaction with various in-game objects indirectly alters Geralt's development. Some items, such as alcohol, potions, or food, contribute to the PC's temporary attribute status, lowering or raising the levels of vitality, vigour, and toxicity. Various combinations of those three factors influence the outcomes of battles. When won, they multiply the number of the PC's XPs, contributing to the acquisition of talents, which are then 
distributed across various attributes and fighting styles. Other objects, for instance books and scrolls, do not cause immediate change, but, when combined with other props (alchemical substances and herbs) enable the PC to use the acquired knowledge to make potions, petards, or recognise and collect necessary herbs. Quest items, on the other hand, are indispensable to proceed in the storyline. Without them, Geralt cannot complete the main quests in Chapter I and advance to Chapter II in Vizima.

Another important aspect refers to the number of functional and stage characters present in the gameworld. Fewer stage characters performing purely decorative roles, and more functional NPCs contribute to a more intricate characterization process of the PC. In The Witcher many in-game characters do not contribute to Geralt's development and cannot be interacted with or the interaction is limited. Also, Geralt's flexibility in dealing with NPCs is limited and has to comply with the game's narrative. The PC cannot thus kill his allies or refuse a battle with the Salamandra. Since the storyline is an important factor (the games are divided into Prologue, Chapters, and Epilogue), the player character needs to comply with its assumptions. Sandbox type or open world games include fewer restrictions as the story is based on loose individual quests and may be altered depending on the player's choices (e.g. Fallout 3).

The last point refers to the significance of selecting dialogue options, which in figure 3 is referred to as interaction mapping. Most of the dialogues with functional characters do not offer significant choices that could change the course of the story or the NPC's attitude towards Geralt. There are, however, certain turning points in the game that include crucial dialogue exchanges with non-player agents. One of the most illustrative examples involves Geralt's interaction with the Scoia'tael warriors at the riverbank after killing the Drowners for Haren Brogg. Geralt can either let the warriors take Haren's supplies (in which case he receives 200 Orens) or kill them. Both decisions have further impact on the storyline in Chapter II. If the Scoia'taels take the cargo, they are stronger and better equipped in further parts of the game.

The discussed elements (props, NPCs, their influence upon the PC, and the role of the player's choice) lead to the emergence of the so called social and environmental presence - the former denoting the extent to which other NPCs react to the PC, and the latter indicating the extent to which the environment itself notices the player character (Heeter 1992, quoted in Nitsche 2008: 205). The extent of the socio-environmental presence in the gameworld determines the strength of the player's agency, their impact upon the PC's development, and the perceived variety of choices. In The Witcher not all the NPCs react to the PC with an equal degree of diversity. The most complex interaction is performed with relation to NPAs, who have more than one simple 
action at their disposal. The PC can, for instance, exchange meaningful dialogue lines with them (by meaningful I mean leading to further implications in the game), and additionally trade, play dice poker or ally in the battle. Cast characters exemplify a lower degree of social presence as they serve a limited purpose in the game. It is also worth noting that the actions triggered by the objects attached to cast characters lead only to temporary changes in the PC (lost vitality, distorted vision), and do not have a long-lasting impact on the overall characterization process. The last category of NPCs (stage characters) does not contribute to the creation of social presence as the PC cannot interact with them. Random villagers or chickens and other domestic animals scattered around the Outskirts do not respond to the PC's actions and constitute purely decorative elements.

The environmental presence is created by the inanimate elements of the game space, such as props. Similarly to non-player characters, objects are divided into categories depending on their level of functionality. Table 3 presents various in-game props that can or cannot be interacted with. The most interactive objects are the functional ones and these create the feeling of presence in the gameworld. By collecting (e.g., weapons, herbs), opening (e.g., door, barrels, wardrobes), reading (e.g., books and scrolls) or consuming them (e.g., water, grapes, potions) the PC leaves traces of his presence in the gameworld. The more functional objects there are, the higher the level of perceived agency and control over the character's shape. It should be also emphasised that different players may construct the character differently not only by assigning different attributes or selecting varying dialogue options, but also by interacting with certain objects that cause permanent changes in the PC. Similarly to stage characters, decorative elements do not contribute to the creation of environmental presence.

\section{Conclusions}

The discussed conceptual framework for PC research in video games has been developed from the researcher-as-player perspective. The strength of the proposed approach lies in its contribution to the practice of reading and interpreting games, not only of making them. It will hopefully become the starting point in numerous other studies, in which the player character is at the heart of gameplay and analytical experience. The Player Character Grid may lead to numerous additional research questions that may incite future research.

After implementing game-specific adjustments, the model could be applied to other ludic forms featuring player characters, such as online cRPGs (e.g. World of Warcraft) or action adventure 
games (e.g. Assassin's Creed series, Ubisoft, Gameloft, Griptonite Games 2007-2014). The examination of the PC could even be extended to more distant genres, such as god games and life simulations, for instance The Sims and Spore. It would be interesting to observe what elements of the model are applied in the construction of a character in a genre different to a role-playing game.

The current model may also be an inspiration for implementing a historical perspective into the PC research. It could be used as a comparative tool for the study of characters in contemporary and past cRPGs. In particular, it would be interesting to juxtapose games from the Silver Age (1980-1986) - a period in the cRPG history when the prototypes of the genre were designed (Barton 2008: 64) - to recent titles created in the Modern Age (2001-present). Such a historical overview would demonstrate the progression of the PC in cRPGs, and as a result depict current trends in game design and preferences in their reception. The findings might also address the issue of whether and how the immersive experience of embodying a VG character has changed over years.

As a closing remark, I would like to briefly touch upon the question of research utility, which is raised particularly often with reference to game studies. Theoretical perspectives may become fruitful sources of inspiration and knowledge for practitioners. They should not, however, be created strictly with a perspective of being valid only when applied in a practical scenario. They represent a perceptive and intellectual process of interpreting a cultural text, both on the level of its wider cultural significance and its pure form. Oftentimes, the paths of theory and practice cross in unexpected moments and configurations, irrespective of whether the theory in question has been developed with practical usage in mind. Vladimir Propp's Morphology of the Folktale (originally published in 1928) has often reappeared with reference to game design, for example in Video Games. A Popular Culture Phenomenon (Berger 2002). Also, the concept of the monomyth or the hero's journey by Joseph Campbell in The Hero with a Thousand Faces (1949) has had its second life in game design, for instance in one of the course books on game story and character development (Krawczyk and Novak 2006). ${ }^{5}$

The potential of the Player Character Grid and its Pivot Player Character Model as a practical tool remains to be seen and judged by the game design community. The proposed framework may equip the players and designers with a language to talk about player character reception and construction. Structures and models help to observe regularities, which turn out useful in coming up with innovative ideas in player character design. After all, to think outside of the box, one needs to realise and understand the existence of the box in the first place. 


\section{References}

Aarseth, E. (2004), Genre Trouble: Narrativism and the Art of Simulation. In: P. Harrigan \& N. Wardrip-Fruin, eds. First Person: New Media as Story, Performance and Game. Cambridge, MA: MIT Press, pp. 45-55.

Adams, E. \& Rollings, A. (2007), Fundamentals of Game Design. New Jersey: Pearson Prentice Hall.

Barton, M. (2008), Dungeons and Desktops: the History of Computer Role-Playing Games. Wellesley, MA: A K Peters.

Berger, A. A. (2002), Video Games: A Popular Culture Phenomenon. Transaction Publishers. Bethesda Game Studios (2008), Fallout 3, Rockville, MD: Bethesda Softworks. BioWare (2002), Neverwinter Nights, Paris: Infogrames/Atari MacSoft. BioWare (2007), Mass Effect, Redwood City, CA: Electronic Arts. Blizzard Entertainment (2004), World of Warcraft, Irvine, CA: Blizzard Entertainment. Boellstorff, T. (2008), Coming of Age in Second Life. An Anthropologist Explores the Virtually Human. Princeton, NJ: Princeton University Press.

Bogost, I. (2006), Unit Operations: An Approach to Videogame Criticism. Cambridge, MA: MIT Press.

Bryce, J. \& Rutter, J. (2005), Gendered Gaming in Gendered Space. In: J. Raessens \& J. Goldstein, eds. Handbook of Computer Game Studies. Cambridge, MA: MIT Press, pp. 301311.

Campbell, J. (1949), The Hero with a Thousand Faces. Pantheon Books.

Carr, D. (2002), Playing with Lara. In: G. King \& T. Krzywinska, eds. Screenplay: cinema/videogames/interfaces. London: Wallflower Press.

CD Projekt RED (2007), The Witcher, Paris: Atari.

Consalvo, M. \& Dutton, N. (2006), Game analysis: Developing a methodological toolkit for the qualitative study of games. Game Studies, 6 (1), http://gamestudies.org/0601/articles/consalvo_dutton. Accessed 1 October 2013.

Doyle, D. (2009), The body of the avatar: rethinking the mind-body relationship in virtual worlds. Journal of Gaming and Virtual Worlds, 1 (2), pp. 131-141. Bristol: Intellect.

EA Digital Illusions CE (2008), Mirror's Edge, Redwood City, CA: Electronic Arts. 
Egenfeldt-Nielsen, S. Heide-Smith, J. \& Pajares Tosca, S. (2008), Understanding Video Games: The Essential Introduction. New York and London: Routledge.

Ensslin, A. (2009), Respiratory Narrative: Multimodality and Cybernetic Corporeality in "Physio-Cyertext”. In: R. Page, ed. New Perspectives on Narrative and Multimodality. New York and London: Routledge.

Frasca, G. (2003), Ludologists Love Stories Too: Notes from a Debate that Never Took Place. In: M. Copier \& J. Raessens, eds. Level Up: Digital Games Research Conference Proceedings. Utrecht: DiGRA and University of Utrecht, http://www.digra.org/dl/db/05163.01125. Accessed 15 October 2013.

Graner Ray, S. (2004), Gender Inclusive Game Design: Expanding the Market. Hingham, MA: Charles River Media.

Howard, J. (2008), Quests: Design, Theory, and History in Games and Narratives. Wellesley, MA: A K Peters.

Kennedy, H. W. \& Dovey, J. (2006), Game Cultures: Computer Games as New Media. Berkshire: Open University Press.

Kennedy, H. W. (2002), Lara Croft: Feminist Icon or Cyberbimbo? On the Limits of Textual Analysis. Game Studies, 2 (2), http://www.gamestudies.org/0202/kennedy. Accessed 27 October 2013.

Lankoski, P. (2003), Characters in Computer Games: Toward Understanding Interpretation and Design. Proceedings of DiGRA Level Up Conference. http://www.digra.org/dl/order_by_author?publication=Level\%20Up\%20Conference\%20Proc eedings. Accessed 25 September 2013.

Maxis (2008), Spore, Redwood City, CA: Electronic Arts.

Morie, J. F. (2007), Performing in (virtual) spaces: Embodiment and being in virtual environments. International Journal of Performance Arts and Digital Media, 3 (2\&3). Bristol: Intellect, pp. 123-138.

Newman, J. (2002), The Myth of the Ergodic Videogame: Some Thoughts on PlayerCharacter Relationship in Videogames. Game Studies: The International Journal of Computer Game Research, 2 (1), http://www.gamestudies.org/0102/newman. Accessed 2 November 2013. 
Newman, J. (2004), Videogames. New York and London: Routledge.

Nitsche, M. (2008), Video Game Spaces. Cambridge, MA: MIT Press.

Novak, J. \& Krawczyk, M. (2005), Game Development Essentials: Game Story and

Character Development. Clifton Park, NY: Delmar Cengage Learning.

Parsler, J. (2010), The non-player agent in computer role-player games, Journal of Gaming and Virtual Worlds, 2 (2), pp. 135-143. Bristol: Intellect.

Perlin K. (2004), Can there be a form between a Game and a Story? In: N. Wadrip-Fruin \& P. Harrigan, eds. First Person: New Media as Story, Performance and Game. New York and London: MIT Press.

Pisarski, M. \& Sikora, D. (2009), Czas bohaterów. Badania postaci w komputerowej grze fabularnej, http://www.hc.amu.edu.pl/numery/5/pisarsikora.pdf. Accessed 1 October 2013.

Propp, V. (2003), Morphology of the Folktale. University of Texas Press.

Ramage, J. (1986), Review of After Strange Texts: The Role of Theorey in the Study of Literature. In Rocky Mountain Review of Language and Literature. Vol. 40, No. 1/2, pp. 105107. Rocky Mountain Modern Language Association.

Rehak, B. (2003), Mapping the Bit Girl: Lara Croft and New Media Fandom. Information, Communication and Society, 6 (4), pp. 477-496. New York and London: Routledge.

Richard, B. \& Zaremba, J. (2005), Gaming with Grrls: Looking for Sheroes in Computer Games. In: J. Raessens \& J. Goldstein, eds. Handbook of Computer Game Studies. Cambridge, MA: MIT Press.

Rockstar North (2008), Grand Theft Auto IV, New York City, NY: Rockstar Games.

Rubenstein, A. (2007), Idealising Fantasy Bodies. Iris Gaming Network, http://theirisnetwork.org/2007/05/26/idealizing-fantasy-bodies. Accessed 26 October 2013.

Schleiner, A. M. (2000), Does Lara Croft Ware Fake Polygons: Gender Analysis of the '1st person shooter/adventure game with female heroine' and Gender Role Subversion and Production in the Game Patch, http://switch.sjsu.edu/web/v4n1/annmarie.html. Accessed 20 September 2013.

Schmieder, Ch. (2009), World of Maskcraft vs. World of Queercraft? Communication, sex and gender in the online role-playing game World of Warcraft. Journal of Gaming and Virtual Worlds, 1 (1), pp. 5-21. Bristol: Intellect. 
Taylor, T.L. (2003), Intentional Bodies: Virtual Environment and the Designers that Shape Them, International Journal of Engineering Education, 19 (1), pp. 25-34.

Taylor, T.L. (2002), Living Digitally: Embodiment in Vritual Worlds. In: R. Schroeder, ed.

The Social Life of Avatars: Presence and Interaction in Shared Virtual Environments.

London: Springer-Verlag, p. 41.

The Witcher (CD Projekt RED 2007)

Turkle, S. (1984), The Second Self: Computers and the Human Spirit. New York, NY: Simon \& Schuster.

Turkle, S. (1995), Life on the Screen: Identity in the Age of the Internet. New York, NY:

Simon \& Schuster.

Turkle, S. (1999), Cyberspace and Identity Source. Contemporary Sociology, 28 (6), pp. 643648. American Sociological Association, http://www.jstor.org/stable/2655534. Accessed 10 October 2013.

Ubersfeld, A. (1999), Reading Theatre I. Toronto: University of Toronto Press.

Ubisoft Montreal, Annecy, Sofia, Milan, Toronto; Gameloft, Griptonite Games (2007-2014), Assassin's Creed series, Montreuil: Ubisoft.

Ubisoft Montreal (2008), Prince of Persia, Montreuil: Ubisoft.

Vogler, Ch. (2007). The Writer's Journey: Mythic Structure For Writers. Michael Wiese Productions.

Wolf J.P., M. (2002), The Medium of the Video Game. Austin, TX: University of Texas Press. Zagal, J. (2005), Towards an Ontological Language for Game Analysis. Paper presented at the Changing Views: Worlds in Play: Digital Games Research Conference, Vancouver, USA, http://users.soe.ucsc.edu/ michaelm/publications/zagal-digra2005.pdf. Accessed 1 October 2013.

1 This multidisciplinary approach to culture may draw on: semiotics, feminism, deconstruction, psychoanalysis or gender studies among others.

${ }^{2}$ An object or a prop in may also be referred to as an "entity". Such terminology is used by Bogost and Mateas, who define it as an element involved in the dynamics of the system, and 
producing meaning (2011: 3$)$.

${ }^{3}$ Interface may be perceived as a dividing layer, which separates players and their actual bodies from the video game characters impersonated on the screen. The players cannot merge with the PCs and literally see the virtual world through their eyes. The interface is there to break the suspension of disbelief and to remind the players of their dual nature with relation to the game. The introduction of controller-free hardware (Microsoft's Kinect) seems to be blurring this boundary by limiting the on-screen interface and removing the hardware, such as game pads, keyboard, mouse, joystick etc. The players use their own body to control their avatars and in doing so, decrease the distance between themselves and the virtual personas they embody. On the other hand, the interface (especially the natural user interface used in Kinect) may be perceived as means - far from being perfect - to join the player with the embodied avatar. The Gibsonian dream of obtaining a pure connection with the technological medium is being partially realised by granting more control to the player over their virtual bodies displayed on the screen.

${ }^{4}$ Temeria (The Witcher) - one of the northern kingdoms with its capital in Vizima. The plot of The Witcher is set in Temeria.

${ }^{5}$ Or third, if we take into consideration its direct influence upon The Writer's Journey: Mythic Structure For Writers by Christopher Vogler, written as a Hollywood screenwriting textbook. 